Psychological Medicine

http://journals.cambridge.org/PSM

Additional services for Psychological Medicine:

PSYCHOLOGICAL

MEDICINE

Email alerts: $\underline{\text { Click here }}$

Subscriptions: $\underline{\text { Click here }}$

Commercial reprints: $\underline{\text { Click here }}$

Terms of use : $\underline{\text { Click here }}$

\title{
How does cognitive behaviour therapy reduce fatigue in patients with chronic fatigue syndrome? The role of physical activity
}

\author{
J. F. Wiborg, H. Knoop, M. Stulemeijer, J. B. Prins and G. Bleijenberg
}

Psychological Medicine / Volume 40 / Issue 08 / August 2010, pp 1281 - 1287

DOI: 10.1017/S0033291709992212, Published online: 05 January 2010

Link to this article: http://journals.cambridge.org/abstract S0033291709992212

How to cite this article:

J. F. Wiborg, H. Knoop, M. Stulemeijer, J. B. Prins and G. Bleijenberg (2010). How does cognitive behaviour therapy reduce fatigue in patients with chronic fatigue syndrome? The role of physical activity. Psychological Medicine, 40, pp 1281-1287 doi:10.1017/S0033291709992212

Request Permissions : $\underline{\text { Click here }}$ 


\title{
How does cognitive behaviour therapy reduce fatigue in patients with chronic fatigue syndrome? The role of physical activity
}

\author{
J. F. Wiborg*, H. Knoop, M. Stulemeijer, J. B. Prins and G. Bleijenberg \\ Expert Centre Chronic Fatigue and Department of Medical Psychology, Radboud University Nijmegen Medical Centre, The Netherlands
}

Background. Cognitive behaviour therapy (CBT) is known to reduce fatigue severity in chronic fatigue syndrome (CFS). How this change in symptomatology is accomplished is not yet understood. The purpose of the present study was to determine whether the effect of CBT on fatigue is mediated by an increase in physical activity.

Method. Three randomized controlled trials were reanalysed, previously conducted to evaluate the efficacy of CBT for CFS. In all samples, actigraphy was used to assess the level of physical activity prior and subsequent to treatment or a control group period. The mediation hypothesis was analysed according to guidelines of Baron \& Kenny [Journal of Personality and Social Psychology (1986) 51, 1173-1182]. A non-parametric bootstrap approach was used to test statistical significance of the mediation effect.

Results. Although CBT effectively reduced fatigue, it did not change the level of physical activity. Furthermore, changes in physical activity were not related to changes in fatigue. Across the samples, the mean mediation effect of physical activity averaged about $1 \%$ of the total treatment effect. This effect did not yield significance in any of the samples.

Conclusions. The effect of CBT on fatigue in CFS is not mediated by a persistent increase in physical activity.

Received 28 January 2009; Revised 24 August 2009; Accepted 19 November 2009; First published online 5 January 2010

Key words: Chronic fatigue syndrome, cognitive behaviour therapy, mechanisms of change, mediation analysis, physical activity.

\section{Introduction}

Chronic fatigue syndrome (CFS) is characterized by a severe and disabling fatigue which persists at least 6 months and which is not the result of a medical condition or ongoing exertion (Fukuda et al. 1994). Cognitive behaviour therapy (CBT) has been shown to reduce fatigue severity and impairment in patients with CFS (Malouff et al. 2008; Price et al. 2008). This effect has often been attributed to an increase in activity because activity programmes have traditionally played a central role in CBT for CFS (Sharpe et al. 1996; Deale et al. 1997; Bleijenberg et al. 2003; Quarmby et al. 2007). In the present study, we tested a treatment model in which the effect of CBT on fatigue is mediated by an increase in physical activity.

Several studies have demonstrated that the average level of physical activity in CFS patients is substantially lower than in healthy controls (e.g. van der Werf

\footnotetext{
* Address for correspondence: J. F. Wiborg, Expert Centre Chronic Fatigue, Radboud University Nijmegen Medical Centre, PO Box 9101, 6500 HB, The Netherlands.

(Email: j.wiborg@nkcv.umcn.nl)
}

et al. 2000; Black et al. 2005). A low level of physical activity has also been shown to perpetuate the feeling of severe fatigue in patients with CFS (Vercoulen et al. 1998). In some approaches of CBT for CFS (e.g. Bleijenberg et al. 2003), an increase in physical activity is stimulated systematically by asking patients to take short walks on a daily basis which are gradually extended in duration up to twice per $\mathrm{h}$ per day. Illnessrelated cognitions are also targeted in these interventions. In particular, patients' preoccupation with their condition and their belief that they have little control over their symptoms are challenged. These cognitions have been found to perpetuate fatigue in CFS as well (Vercoulen et al. 1998).

There are behavioural interventions for CFS which rely exclusively on a physical activity programme to improve fatigue. According to the rationale of graded exercise therapy (GET), the key problem in CFS is physical deconditioning which can be overcome by enhancing the level of physical fitness (Fulcher \& White, 1997; Wearden et al. 1998). Patients are stimulated to gradually increase their level of physical activity on exercise bikes or other equipment. Illnessrelated cognitions are not challenged intentionally. 
This strategy has been shown to reduce fatigue in CFS as well (Larun et al. 2004; Chambers et al. 2006).

By now, a substantial body of research is available to support the efficacy of interventions for CFS in which the level of physical activity is targeted. However, considerably less attention has been paid to whether the effect of these interventions actually depends on a change in physical parameters. Such a finding would be vital to the validation of all treatment models which rely on a physical activity programme in some way to improve fatigue. In the only study of such nature that we are aware of, MossMorris et al. (2005) demonstrated that an increase in physical fitness does not contribute to the treatment effect of GET on fatigue in CFS.

The purpose of the present study was to determine whether the treatment effect of CBT on fatigue is mediated by an increase in physical activity. In psychotherapy research, testing mediation is a strategy to identify variables which intervene in the relationship between treatment and outcome and thereby help to better understand how treatment works (Frazier et al. 2004). This idea is illustrated in Fig. 1. In Fig. 1a, a change in fatigue is simply explained by the allocation of treatment (path c). This model is usually tested when the efficacy of an intervention is of primary interest to the investigator. In Fig. $1 b$, the effect of CBT on fatigue (path $c^{\prime}$ ) is mediated by a change in physical activity (path a) which is responsible for the change in fatigue (path $b$ ). We tested this mediation hypothesis to gain more insight into how CBT reduces fatigue in CFS.

\section{Method}

For the purpose of the present study we reanalysed three randomized controlled trials (RCT), previously conducted to test the efficacy of CBT on CFS (Prins et al. 2001; Stulemeijer et al. 2005; Knoop et al. 2008). Treatment was based on the manual of CBT for CFS described in detail by Bleijenberg et al. (2003) and effectively reduced fatigue severity in all trials. Patients were randomly assigned to either a treatment or a control group condition. Assessment took place prior and subsequent to treatment or the control group period.

\section{Samples}

The first of the three RCTs evaluated the effect of CBT on CFS (Prins et al. 2001). All patients were aged between 18 and 60 years and met the Centers for Disease Control and Prevention (CDC) research criteria for CFS (Fukuda et al. 1994), except for the four additional symptoms criterion. In total, 270 patients (a)

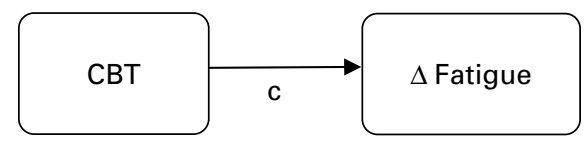

(b)

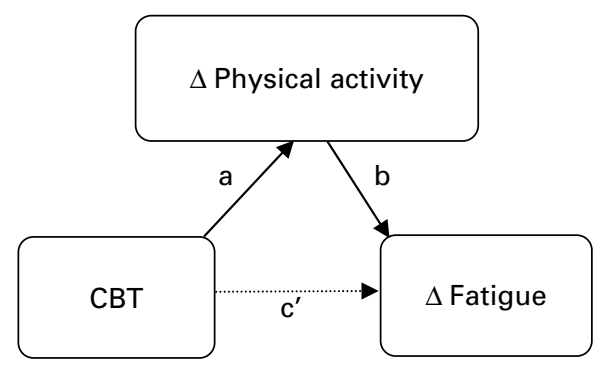

Fig. 1. The effect of cognitive behaviour therapy (CBT) on fatigue without $(a)$ and with $(b)$ the hypothesized mediator changes in physical activity.

were assigned to either CBT, a guided support group, or a natural course condition. CBT consisted of 16 sessions of $1 \mathrm{~h}$ over 8 months while the guided support group had 11 meetings of 1.5 h over 8 months. All groups were assessed at baseline and 8 months later (second assessment). The results of the guided support group and the natural course condition were comparable in the original study (Prins et al. 2001). We therefore approached the two control groups as one in our analyses.

The second RCT tested the effect of guided selfinstructions on CFS (Knoop et al. 2008). This minimal intervention consisted of written self-instructions combined with email contact with a trained therapist. All patients were aged 18 years or older and met the 1994 CDC research criteria for CFS (Fukuda et al. 1994). In total, 169 patients were assigned to either the guided self-instructions or a waiting list control condition. The time between baseline and second assessment varied between 6 and 12 months with a mean time of 10.5 (S.D. $=4.0)$ months in the treatment group and 9.7 (S.D. =3.6) months in the control group.

The third RCT evaluated the effect of CBT in adolescents with CFS (Stulemeijer et al. 2005). In total, 69 patients were assigned to either CBT or a waiting list condition. All patients were aged between 10 and 17 years and met the 1994 CDC research criteria for CFS (Fukuda et al. 1994). Both groups were assessed at baseline and 5 months later (second assessment). CBT consisted of 10 sessions of $1 \mathrm{~h}$ over 5 months. Parents of the adolescent patients were actively involved in the treatment process. 


\section{Instruments}

Fatigue

The subscale fatigue severity of the Checklist Individual Strength (CIS) was used to indicate the severity of fatigue experienced by patients. It consists of eight items which are scored on a seven-point Likert scale. The sum score varies between 8 , no fatigue, and 56, severe fatigue. The CIS is a reliable and valid instrument for the assessment of fatigue in CFS (Vercoulen et al. 1994; Dittner et al. 2004). A common cut-off score for severe fatigue is 35 (or higher), which is about two standard deviations above the norm score for healthy patients.

\section{Physical activity}

Actigraphy was used to assess physical activity in all trials. The Actometer is a motion-sensing device which is worn around the ankle for 12 consecutive days. An average daily level of physical activity is computed over this period, with higher scores indicating more physical activity. The Actometer is described in more detail by van der Werf et al. (2000). They found a significant difference between the mean Actometer score of CFS patients which was 66 (S.D. = 22) and healthy controls who had a mean Actometer score of 91 (s.D. $=25$ ). They also identified a group of patients who scored below the mean score of CFS patients on 11 out of 12 days and labelled this group as pervasively passive. We excluded all patients from our study who missed actigraphy at second assessment.

\section{Analyses}

We conducted one-way analysis of variance tests to test whether those patients who were excluded from our study due to missing actigraphy at second assessment differed on baseline characteristics from those patients who were included. Fisher's exact test was used in the case of dichotomous dependent variables.

A macro expansion for SPSS introduced by Preacher \& Hayes (2004) was employed to conduct mediation analysis. The macro followed the standard for mediation analysis introduced by Baron \& Kenny (1986). Paths a, b, c and c' of Fig. 1 were analysed using regression analysis. To examine path a, changes in physical activity were regressed on treatment. Path $b$ was examined by regressing changes in fatigue on changes in physical activity, correcting for treatment. In the case of path c, changes in fatigue were regressed on treatment, while path $c^{\prime}$ was examined by regressing changes in fatigue on treatment, this time correcting for the mediator changes in physical activity. The size of the mediation effect was computed by multiplying path a with path $b$.

Statistical significance of the mediation effect was tested using a non-parametric bootstrap approach (Preacher \& Hayes, 2004). The observed dataset was randomly resampled 5000 times with replacement which resulted in 5000 samples with mediation effect. The mean of these mediation effects was used as a population parameter. When the $95 \%$ confidence interval (CI) around this parameter did not include zero, the null hypothesis was rejected. When the $95 \%$ CI did include zero, the mediation hypothesis was rejected. This procedure increased the power to detect significant effects in small, non-normally distributed samples.

We analysed each trial separately because patient population (adult versus adolescent) as well as presentation of treatment (face-to-face contact versus guided self-instructions) differed considerably between the trials. Since we examined three individual trials in one study, we preferred a $p$ value of $\leqslant 0.017$ as the threshold for significance ( $0.050 \mathrm{div}$ ided by 3). All change scores were computed by subtracting second from baseline assessment. A negative change score indicated a decrease while a positive one indicated an increase on the respective variable.

\section{Results}

In Table 1, the baseline characteristics of the patients who were included in our study are compared with those patients who were excluded due to missing actigraphy at second assessment. As shown, none of the differences between these two groups yielded significance in our analyses.

In Table 2, baseline, second assessment and change scores on fatigue severity and physical activity are presented per treatment condition for the group of included patients. In Table 3 , it can be seen that fatigue reduced significantly more in the treatment group than in the control group in all samples (path c). However, CBT did not produce a significant change in physical activity in any of the samples (path a). There was also no significant relationship between changes in physical activity and changes in fatigue (path b). The effect of treatment on fatigue remained significant when it was controlled for changes in physical activity (path $\mathrm{c}^{\prime}$ ).

In Table 4, results of the bootstrap analysis are shown. Resampling of the observed dataset resulted in a mean mediation effect with a $95 \%$ CI for each sample. The mean mediation effect averaged about $1 \%$ 
Table 1. Baseline characteristics of included versus excluded patients

\begin{tabular}{|c|c|c|c|c|c|c|}
\hline & \multicolumn{2}{|c|}{ Prins et al. (2001) } & \multicolumn{2}{|c|}{ Knoop et al. (2008) } & \multicolumn{2}{|c|}{ Stulemeijer et al. (2005) } \\
\hline & Included & Excluded & Included & Excluded & Included & Excluded \\
\hline$n(\mathrm{CBT})$ & $211(70)$ & $59(22)$ & $132(58)$ & $37(26)$ & $58(28)$ & $11(7)$ \\
\hline Age, years & $36.9(10.2)$ & $36.0(9.7)$ & $37.9(10.4)$ & $38.4(10.1)$ & $15.7(1.3)$ & $15.4(0.8)$ \\
\hline$F$ & \multicolumn{2}{|c|}{0.37} & \multicolumn{2}{|c|}{0.08} & \multicolumn{2}{|c|}{0.48} \\
\hline$p$ & \multicolumn{2}{|c|}{0.543} & \multicolumn{2}{|c|}{0.785} & \multicolumn{2}{|c|}{0.493} \\
\hline Percentage female $(n)$ & 78 (165) & $80(47)$ & 77 (101) & $89(33)$ & $90(52)$ & $81(9)$ \\
\hline$p^{\mathrm{a}}$ & \multicolumn{2}{|c|}{0.860} & \multicolumn{2}{|c|}{0.111} & \multicolumn{2}{|c|}{0.604} \\
\hline Illness duration, years & $5.5(5.4)$ & $6.0(6.3)$ & $9.7(9.9)$ & $12.0(10.9)$ & $1.8(1.3)$ & $1.7(1.2)$ \\
\hline$F$ & \multicolumn{2}{|c|}{0.33} & \multicolumn{2}{|c|}{1.56} & \multicolumn{2}{|c|}{0.03} \\
\hline$p$ & \multicolumn{2}{|c|}{0.566} & \multicolumn{2}{|c|}{0.213} & \multicolumn{2}{|c|}{0.865} \\
\hline Fatigue severity & $52.0(4.1)$ & $52.9(3.4)$ & $49.6(5.4)$ & $49.2(5.4)$ & $51.8(4.3)$ & $53.4(2.7)$ \\
\hline$F$ & \multicolumn{2}{|c|}{2.46} & \multicolumn{2}{|c|}{0.16} & \multicolumn{2}{|c|}{1.34} \\
\hline$p$ & \multicolumn{2}{|c|}{0.118} & \multicolumn{2}{|c|}{0.692} & \multicolumn{2}{|c|}{0.251} \\
\hline Physical activity & $65.4(20.4)$ & $69.0(26.7)^{\mathrm{b}}$ & $63.3(22.5)$ & $61.9(18.5)$ & $65.3(21.0)$ & $65.7(33.2)$ \\
\hline$F$ & \multicolumn{2}{|c|}{1.21} & \multicolumn{2}{|c|}{0.12} & \multicolumn{2}{|c|}{0.00} \\
\hline$p$ & \multicolumn{2}{|c|}{0.272} & \multicolumn{2}{|c|}{0.733} & \multicolumn{2}{|c|}{0.953} \\
\hline Percentage passive $(n)$ & $25(53)$ & $14(8)$ & $27(35)$ & $24(9)$ & $22(13)$ & $44(4)^{\mathrm{c}}$ \\
\hline$p^{\mathrm{a}}$ & \multicolumn{2}{|c|}{0.077} & \multicolumn{2}{|c|}{1.00} & \multicolumn{2}{|c|}{0.216} \\
\hline
\end{tabular}

CBT, Cognitive behaviour therapy.

Values are given as mean score (standard deviation) unless otherwise indicated; differences were examined with analysis of variance.

${ }^{\text {a }}$ Fischer's exact test.

${ }^{\mathrm{b}}$ One patient missing.

${ }^{\mathrm{c}}$ Two patients missing.

Table 2. Baseline, second assessment and change scores on fatigue severity and physical activity in the group of included patients per treatment condition

\begin{tabular}{|c|c|c|c|c|c|c|}
\hline \multirow[b]{2}{*}{ Treatment condition ... } & \multicolumn{2}{|c|}{ Prins et al. $(2001)(n=211)$} & \multicolumn{2}{|c|}{ Knoop et al. (2008) $(n=132)$} & \multicolumn{2}{|c|}{ Stulemeijer et al. (2005) $(n=58)$} \\
\hline & $\begin{array}{l}\text { CBT } \\
(n=70)\end{array}$ & $\begin{array}{l}\text { Control } \\
(n=141)\end{array}$ & $\begin{array}{l}\text { CBT } \\
(n=58)\end{array}$ & $\begin{array}{l}\text { Control } \\
(n=74)\end{array}$ & $\begin{array}{l}\text { CBT } \\
(n=28)\end{array}$ & $\begin{array}{l}\text { Control } \\
(n=30)\end{array}$ \\
\hline \multicolumn{7}{|l|}{ Fatigue severity } \\
\hline Baseline & $52.4(4.0)$ & $51.7(4.1)$ & $49.5(5.1)$ & $49.6(5.7)$ & $52.3(4.1)$ & $51.3(4.4)$ \\
\hline Second assessment & $40.3(10.5)$ & $45.8(8.7)$ & $38.9(10.8)$ & $45.7(8.9)$ & $24.8(14.1)$ & $42.9(13.9)$ \\
\hline Change score & $-12.1(10.3)$ & $-6.0(9.2)$ & $-10.6(11.1)$ & $-3.9(8.4)$ & $-27.5(14.2)$ & $-8.4(13.4)$ \\
\hline \multicolumn{7}{|l|}{ Physical activity } \\
\hline Baseline & $67.4(21.8)$ & $64.5(19.7)$ & $63.1(23.5)$ & $63.5(21.8)$ & $65.6(22.4)$ & $65.0(20.1)$ \\
\hline Second assessment & $68.8(25.2)$ & $64.9(21.7)$ & $67.3(22.5)$ & $67.8(21.4)$ & $75.8(21.7)$ & $67.7(23.8)$ \\
\hline Change score & $1.4(18.5)$ & $0.4(16.4)$ & $4.3(20.4)$ & $4.3(21.0)$ & $10.3(21.7)$ & $2.7(28.1)$ \\
\hline
\end{tabular}

CBT, Cognitive behaviour therapy.

Values are given as mean (standard deviation).

of the total treatment effect across the three samples. The $95 \%$ CI of the mean mediation effect included zero in all samples. The mediation hypothesis was not confirmed.

\section{Discussion}

The data did not support a treatment model in which the effect of CBT on fatigue is mediated by an increase 
Table 3. Testing paths $a, b, c$ and $c^{\prime}$ as depicted in Fig. 1

\begin{tabular}{lcccc}
\hline & Path a & Path b & Path c & Path c' \\
\hline $\begin{array}{c}\text { Prins et al. } \\
\text { (2001) }\end{array}$ & & & & \\
$B$ & 0.99 & -0.04 & -6.11 & -6.07 \\
S.E. & 2.50 & 0.04 & 1.40 & 1.40 \\
$t$ & 0.40 & -1.07 & -4.36 & -4.33 \\
$p$ & 0.693 & 0.285 & $<0.001$ & $<0.001$ \\
Knoop et al. & & & & \\
$(2008)$ & & & & \\
$B$ & -0.00 & -0.08 & -6.64 & -6.64 \\
S.E. & 3.64 & 0.04 & 1.70 & 1.68 \\
$t$ & -0.00 & -2.00 & -3.91 & -3.95 \\
$p$ & 0.999 & 0.047 & $<0.001$ & $<0.001$ \\
Stulemeijer & & & & \\
et al. (2005) & & & & \\
$B$ & 7.58 & -0.10 & -19.10 & -18.35 \\
S.E. & 6.63 & 0.07 & 3.63 & 3.64 \\
$t$ & 1.14 & -1.40 & -5.27 & -5.04 \\
$p$ & 0.257 & 0.178 & $<0.001$ & $<0.001$ \\
\hline & & & &
\end{tabular}

S.E., Standard error.

in physical activity. CBT did neither cause an increase in physical activity at the end of treatment (path a) nor was an increase in physical activity associated with a reduction in fatigue (path $b$ ). A formal test of the mediation effect confirmed that CBT yielded its effect independent of a persistent change in physical activity.

These results are in line with the study of MossMorris et al. (2005) in which it was demonstrated that not an increase in fitness but a change in preoccupation with symptoms mediated the effect of GET on fatigue. The results are also consistent with earlier research on CBT for CFS in which a reduction in fatigue was associated with a change in illness beliefs (Deale et al.1998). In the light of these findings, changing illness-related cognitions seems to play a more crucial role in CBT for CFS than an increase in physical activity.

There are several potential alternative explanations for the fact that we did not find support for our mediation hypothesis. A substantial amount of patients did not complete actigraphy at second assessment and had to be excluded from our mediation analyses. It is possible that we introduced a bias through exclusion which might account for our findings. However, analysis of the baseline characteristics revealed that a selection bias is no likely explanation for our findings.

Our patients were not required to stick to their physical activity programme until the end of therapy. As treatment proceeded, they were allowed to substitute physical activities for other activities such as
Table 4. Testing the mediation effect according to the bootstrap approach

\begin{tabular}{lccc}
\hline & $\begin{array}{l}\text { Prins et al. } \\
(2001)\end{array}$ & $\begin{array}{l}\text { Knoop et al. } \\
(2008)\end{array}$ & $\begin{array}{l}\text { Stulemeijer } \\
\text { et al. (2005) }\end{array}$ \\
\hline $\begin{array}{l}\text { Mean mediation } \\
\text { effect }\end{array}$ & -0.03 & 0.01 & -0.61 \\
Lower 95\% CI & -0.39 & -0.69 & -2.19 \\
Upper 95\% CI & 0.27 & 0.76 & 0.86 \\
$\begin{array}{l}\text { Total treatment } \\
\text { effect, \% }\end{array}$ & 0.5 & -0.15 & 3.2 \\
\hline
\end{tabular}

CI, Confidence interval.

social ones. Consistently, treatment could have resulted in a temporary increase in physical activity which was no longer existent when second assessment took place. This temporary increase in physical activity during treatment might have been sufficient to facilitate a persistent change in illness-related cognitions. When patients learned that they were able to increase their level of physical activity despite their symptoms, their belief of having little control over their condition should have changed and with it also the perception of fatigue as an inherently aversive state. To examine these mechanisms of change in CBT for CFS, patients' physical activity and illness-related cognitions need to be monitored repeatedly during treatment.

Patients with a pervasively passive activity pattern have extremely low levels of physical activity. These patients do not respond to common CBT for CFS (Prins et al. 2001). A specifically tailored approach in which the physical activity programme is delivered earlier showed better effects for these patients (e.g. Stulemeijer et al. 2005). They might thus profit from a persistent increase in physical activity after all. Unfortunately, the number of patients was too small to properly examine whether a change in physical activity does mediate the effect of treatment in pervasively passive patients.

In contrast to pervasively passive patients, the majority of CFS patients is not only characterized by a low level of physical activity, but has also a deregulated pattern of physical activity in which short periods of high activity are alternated with longer periods of rest (van der Werf et al. 2000). These patients were taught to spread their activities evenly across day and week (Bleijenberg et al. 2003). Perhaps a change in activity regulation is more important to facilitate improvement in relatively active CFS patients than an increase in physical activity.

Taking these considerations into account, the exact role of physical activity in CBT for CFS remains to be 
determined. Besides physical activity, future investigations should also examine the role of changes in social, mental and work-related activities in CBT for CFS, preferably based on the time patients actually spend on these activities to limit perception bias. For the time being, our study was the first one to show that the severity of fatigue in patients with CFS is not reduced by CBT because patients have become more physically active at the end of their treatment. Based on these findings, physical activity programmes can better be understood as a way to facilitate change in other mechanisms which are more directly related to a change in fatigue. Among these mechanisms, a change in illness-related cognitions is likely to play a crucial role in CBT for CFS and should therefore be monitored closely during treatment.

\section{Acknowledgements}

None.

\section{Declaration of Interest}

None.

\section{References}

Baron RM, Kenny DA (1986). The moderator-mediator variable distinction in social psychological research: conceptual, strategic, and statistical considerations. Journal of Personality and Social Psychology 51, 1173-1182.

Black CD, O'Connor PJ, McCully KK (2005). Increased daily physical activity and fatigue symptoms in chronic fatigue syndrome. Dynamic Medicine 4. Published online: 3 March 2005. doi:10.1186/1476-5918-4-3.

Bleijenberg G, Prins JB, Bazelmans E (2003). Cognitivebehavioral therapies. In Handbook of Chronic Fatigue Syndrome (ed. L. A. Jason, P. A. Fennell and R. R. Taylor), pp. 493-526. Wiley: New York.

Chambers D, Bagnall AM, Hempel S, Forbes C (2006). Interventions for the treatment, management and rehabilitation of patients with chronic fatigue syndrome/ myalgic encephalomyelitis: an updated systematic review. Journal of the Royal Society of Medicine 99, 506-520.

Deale A, Chalder T, Marks I, Wessely S (1997). Cognitive behavior therapy for chronic fatigue syndrome: a randomized controlled trial. American Journal of Psychiatry 154, 408-414.

Deale A, Chalder T, Wessely S (1998). Illness beliefs and treatment outcome in chronic fatigue syndrome. Journal of Psychosomatic Research 45, 77-83.

Dittner AJ, Wessely S, Brown RG (2004). The assessment of fatigue: a practical guide for clinicians and researchers. Journal of Psychosomatic Research 56, 157-170.

Frazier PA, Tix AP, Barron KE (2004). Testing moderator and mediator effects in counseling psychology research. Journal of Counseling Psychology 51, 115-134.
Fukuda K, Straus SE, Hickie I, Sharpe MC, Dobbins JG, Komaroff A (1994). The chronic fatigue syndrome: a comprehensive approach to its definition and study. International Chronic Fatigue Syndrome Study Group. Annals of Internal Medicine 121, 953-959.

Fulcher KY, White PD (1997). Randomised controlled trial of graded exercise in patients with the chronic fatigue syndrome. British Medical Journal 314, 1647-1652.

Knoop H, van der Meer JW, Bleijenberg G (2008). Guided self-instructions for people with chronic fatigue syndrome: randomised controlled trial. British Journal of Psychiatry 193, 340-341.

Larun L, McGuire H, Edmonds M, Odgaard-Jensen J, Price JR (2004). Exercise therapy for chronic fatigue syndrome. Cochrane Database of Systematic Reviews 2004, Issue 3. Art. No.: CD003200. doi: 10.1002/ 14651858.CD003200.pub2.

Malouff JM, Thorsteinsson EB, Rooke SE, Bhullar N, Schutte NS (2008). Efficacy of cognitive behavioral therapy for chronic fatigue syndrome: a meta-analysis. Clinical Psychology Review 28, 736-745.

Moss-Morris R, Sharon C, Tobin R, Baldi JC (2005). A randomized controlled graded exercise trial for chronic fatigue syndrome: outcomes and mechanisms of change. Journal of Health Psychology 10, 245-259.

Preacher KJ, Hayes AF (2004). SPSS and SAS procedures for estimating indirect effects in simple mediation models. Behavior Research Methods, Instruments, and Computers 36, 717-731.

Price JR, Mitchell E, Tidy E, Hunot V (2008). Cognitive behaviour therapy for chronic fatigue syndrome in adults. Cochrane Database of Systematic Reviews 2008, Issue 3. Art. No.: CD001027. doi: 10.1002/14651858. CD001027.pub2.

Prins JB, Bleijenberg G, Bazelmans E, Elving LD, de Boo TM, Severens JL, van der Wilt GJ, Spinhoven P, van der Meer JW (2001). Cognitive behaviour therapy for chronic fatigue syndrome: a multicentre randomised controlled trial. Lancet 357, 841-847.

Quarmby L, Rimes KA, Deale A, Wessely S, Chalder T (2007). Cognitive-behaviour therapy for chronic fatigue syndrome: comparison of outcomes within and outside the confines of a randomised controlled trial. Behaviour Research and Therapy 45, 1085-1094.

Sharpe M, Hawton K, Simkin S, Surawy C, Hackmann A, Klimes I, Peto T, Warrell D, Seagroatt V (1996). Cognitive behaviour therapy for the chronic fatigue syndrome: a randomized controlled trial. British Medical Journal 312, 22-26.

Stulemeijer M, de Jong LW, Fiselier TJ, Hoogveld SW, Bleijenberg G (2005). Cognitive behaviour therapy for adolescents with chronic fatigue syndrome: randomised controlled trial. British Medical Journal 330. Published online: 7 December 2004. doi:10.1136/ bmj.38301.587106.63.

Vercoulen JH, Swanink CM, Fennis JF, Galama JM, van der Meer JW, Bleijenberg G (1994). Dimensional assessment of chronic fatigue syndrome. Journal of Psychosomatic Research 38, 383-392. 
Vercoulen JH, Swanink CM, Galama JM, Fennis JF, Jongen PJ, Hommes OR, van der Meer JW, Bleijenberg G (1998). The persistence of fatigue in chronic fatigue syndrome and multiple sclerosis: development of a model. Journal of Psychosomatic Research 45, 507-517.

van der Werf SP, Prins JB, Vercoulen JH, van der Meer JW, Bleijenberg G (2000). Identifying physical activity patterns in chronic fatigue syndrome using actigraphic assessment. Journal of Psychosomatic Research 49, 373-379.

Wearden AJ, Morriss RK, Mullis R, Strickland PL, Pearson DJ, Appleby L, Campbell IT, Morris JA (1998). Randomised, double-blind, placebo-controlled treatment trial of fluoxetine and graded exercise for chronic fatigue syndrome. British Journal of Psychiatry 172, 485-490. 